\title{
Epidemiology of injuries in female high school soccer players.
}

\author{
Keamogetse Refilwe Sentsomedi ${ }^{1}$, Threethambal Puckree ${ }^{2}$
}

\author{
1. Keamogetse Refilwe Sentsomedi, Field of study:Chiropractic \\ 2.Threethambal Puckree, Faculty of Health Sciences, Field of study: Exercise physiology
}

Work conducted at Durban University of Technology

\begin{abstract}
Background: Sport is a compulsory activity in schools in South Africa. Female learners participating in soccer are more vulnerable to injuries than males.

Objective: This study determined the epidemiology of injuries in female high school soccer players.

Methods: A cross sectional survey captured the epidemiology of injuries in the players. The population included 200 players from 27 high schools in one district between the ages of 14 to 19 years. A self-administered questionnaire was used to collect data.

Results: Only 85 scholars from 8 schools participated. From the 85 respondents, 31 (36.5\%) sustained injuries. Only 61 injuries were reported by the injured players. The injury prevalence for the season was $36.5 \%$. The rate of injury was 90 per 1000 athlete exposure hours during the season. The defenders and midfielders sustained the most injuries. Most injuries reported were contact in nature. More injuries occurred during training than during matches. The lower extremity $(77.8 \%)$ was injured more than the upper extremity $(22.2 \%)$. The knee $(22.2 \%)$ and ankle $(15.9 \%)$ were the most frequently injured body parts. Muscle injury was the most commonly reported followed by bruising.

Conclusion: Prevalence of injuries was high with the lower limb, specifically the knee and ankle being commonly injured.

Keywords: Epidemiology, soccer injuries, youth

DOI: http://dx.doi.org/10.4314/ahs.v16i1.39

Cite as: Sentsomedi KR, Puckree T. Epidemiology of injuries in female high school soccer players. Afri Health Sci. 2016;16(1): 298-305. http:/ / dx.doi.org/10.4314/abs.v16i1.39
\end{abstract}

\section{Introduction.}

In South Africa the increased prevalence of obesity in school children ${ }^{1}$ has refocused attention on the compulsory participation in physical and sporting activity ${ }^{2}$. The interest in school girls participating in soccer was stimulated after the constitution of the South African women's team in 1993 and when the team qualified to compete in the Women's World Cup for the first time in 1994. The South African Football Association (SAFA) currently supports inter-regional tournaments for the women U19 team. This has further stimulated the participation of young females in soccer. ${ }^{3}$. More than 50 000 South African females were registered with the South African Football Association by 20064 .

\section{Corresponding author:}

Threethambal Puckree,

Faculty of Health Sciences

Field of study: Exercise physiology

Tel: 0313732967

E-mail:puckreet@dut.ac.za

Participation in soccer amongst other sports is an effective way for the youth to increase their level of physical activity and fitness. It helps adolescents focus on fun and enjoyment while burning up calories especially when electronic devices distract them from physical activity $^{5}$. Although soccer is not offered to female learners in all public schools, it is gaining popularity in the schools in which it is offered.

Soccer is a demanding sport which requires a combination of endurance, fitness, running and discontinuous sprinting ${ }^{6}$. As such it is associated with injuries. The adolescent learner may be more vulnerable to injuries due to the physiological growth spurt that occurs during the teenage period. The majority of the available literature has focussed on the epidemiology of injuries in adult males who participate in sport $^{7}$ but the body of literature on female soccer players has also grown significant$1 y^{9,10}$. In the last decade, increasing emphasis has been placed on injuries in sports women ${ }^{89}$. The growth in the number of females participating in sports, including soccer has made it necessary to understand the effect 
that sports activities have on female performance and injury patterns ${ }^{8,9}$ especially in resource poor settings.

Le Gall et $\mathrm{al}^{8}$ reported injury rates of 1.2 to 24 per 1000 exposure hours in female soccer players depending on age, level and time in season. Teenage soccer players were found to be at the highest risk for injury. In Europe, the incidence of injuries in teenage female soccer players have been reported to range from 4.6 to 22.4 per 1000 training and match hours respectively in the soccer season ${ }^{8}$. Owoeye et $\mathrm{al}^{10}$ stated that there was a high incidence of injuries sustained by female soccer players (Super Falcons of Nigeria) during the Beijing Olympic games.

With anatomical and physiological differences between young males and females, the injury rate and type are different between the genders. More studies are elucidating injuries in female sports players ${ }^{9,10,11}$, and it is clear that the research findings on male players cannot be applied to females. In South Africa, there are few studies on young female soccer players but no study on the epidemiology of injuries in female soccer players' in the province under study.Therefore the aim of this study was to determine the epidemiology of injuries in female high school soccer players in one district in one province of South Africa.

\section{Methods}

A cross sectional survey was used to determine the epidemiology of injuries in female high school soccer players in one district in one province of South Africa. This study was conducted in high schools in two sub-districts of a selected district in South Africa. There are 60 high schools in the district, but only 27 schools have female soccer programs.

Two hundred soccer playing school girls between the ages of 14 and 19 years from 27 high schools in one district were invited to participate in the study. The population size was 400 and the sample size required was a minimum of 197 participants at a confidence level of $95 \%$. All participants signed a letter of informed assent and were in possession of a signed letter of parental consent if applicable. ${ }^{4}$
The questionnaire was developed based on related literature $e^{6,12,13,14}$ and categorised to gather relevant information to achieve the aims of the study. The closed ended questions elicited information regarding the subjects' demography, injury data, equipment and treatment, as well as medical help sought. The questionnaire was construct and face validated using an expert focus group and a pilot study with eight school girls. The reliability of data collected was ensured by one researcher administering all the questionnaires.

Data was collected in 2013. Permission to conduct the study was obtained from the Department of Education managing education in the province, the principals of the participating schools, parents and the learners. Learners who had consent forms signed by their parents or guardians were given their information letters and the research process explained to all, after which they signed their respective assent forms and completed the questionnaires. Data was analysed using the SPSS version 20.0. Descriptive statistics, Chi square tests, and odds ratios were calculated. Analysis was conducted at the $95 \%$ level of confidence.

\section{Results}

A total of 173 questionnaires from eight high schools in the study district were returned, making up a return rate of $88 \%$. Only eight schools participated in the study because the other 19 schools that offered female soccer were either not currently active in soccer during the study or did not want to participate in the study. Only 85 questionnaires making up $49 \%$ of the total were usable since the others were incomplete and therefore were eliminated from the data analysis.

\section{Demographic profile of the participants}

The participants ranged in age from 14 to 19 years with a mean and standard deviation of $15.85 \pm 1.32$ years. The majority of the participants were 15 years of age $(29.4 \%)$ followed by 16 years of age $(24.7 \%)$. The distribution of participants by district according to race, age, team, player position and participation in other sports are shown in Table 1. 
Table 1: Number and percentage of participants from each sub-district according to race, age, team, player position and other sport played.

\begin{tabular}{|llllllll|}
\hline & & \multicolumn{2}{l}{ Sub-district 1 } & \multicolumn{2}{l|}{ Sub-district 2 } & Total \\
& & $\mathbf{n}$ & $\mathbf{\%}$ & $\mathbf{n}$ & $\mathbf{\%}$ & $\mathbf{n}$ & $\mathbf{\%}$ \\
Race & & $\mathbf{7 0}$ & 82.4 & $\mathbf{1 5}$ & 17.6 & 85 & 100 \\
& Black & 52 & 74.3 & 6 & 40 & 58 & 68.2 \\
& Coloured & 10 & 14.3 & 2 & 13.3 & 12 & 14.1 \\
& Indian & 1 & 1.4 & 1 & 6.7 & 2 & 2.4 \\
& White & 7 & 10 & 6 & 40 & 13 & 15.3 \\
Team by Age & U15 & 26 & 37.1 & 6 & 40 & 32 & 37.6 \\
& U16 & 20 & 28.6 & 7 & 46.7 & 27 & 31.8 \\
& U17 & 7 & 10 & 1 & 6.7 & 8 & 9.4 \\
& U18 & 14 & 20 & 0 & 0 & 14 & 16.5 \\
& U19 & 3 & 4.3 & 1 & 6.7 & 4 & 4.7 \\
& A & 58 & 82.9 & 9 & 60 & 67 & 78.8 \\
& B & 10 & 14.3 & 5 & 33.3 & 15 & 17.6 \\
& C & 2 & 2.9 & 1 & 6.7 & 3 & 3.5 \\
& Goam & 3 & 4.3 & 4 & 26.7 & 7 & 8.2 \\
& Defender & 29 & 41.4 & 4 & 26.7 & 33 & 38.8 \\
& Midfielder & 19 & 27.1 & 6 & 40 & 25 & 29.4 \\
& Striker & 19 & 27.1 & 1 & 6.7 & 20 & 23.5 \\
& Yes & 45 & 64.3 & 9 & 60 & 54 & 63.5 \\
\hline
\end{tabular}

The majority of the players were African Blacks (68\%). The largest number of players in both sub-districts was defenders $(38.8 \%)$, followed by midfielders $(29.4 \%)$ and strikers $(23.5 \%)$. Most of the participants also played other sports $(63.5 \%)$.

\section{Years of participation in school soccer}

The experience of the female soccer players ranged from one year to nine years (mean $=2.92$ years; $\mathrm{SD}=$ 1.88 years). More players, $30.6 \%$ and $22.4 \%$ had one and two years of experience playing school soccer respectively. Twenty seven percent of the respondents had four to nine years of experience playing soccer.

\section{Prevalence of injury}

The majority of the players $(63.5 \%)$ reported no injuries over one season of training and matches. The remaining participants (31) reported a total of 80 injuries. The overall injury prevalence was $36.5 \%$. The rate of injury was 90 per 1000 athlete exposure hours in the season. The majority of injured participants $(61 \%)$ reported one injury. The remaining respondents reported two to five injuries. Table 2 shows the risk estimates. The odds of an injured player sustaining an injury was high.

Table 2: Risk estimates for injury

\begin{tabular}{|llll|}
\hline & Risk & \multicolumn{2}{c|}{$\mathbf{9 5 \%}$ Confidence Interval } \\
& Estimate & Lower & Upper \\
Odds Ratio & 11.250 & 2.035 & 62.195 \\
For cohort with 1 injury & 2.708 & 1.168 & 6.281 \\
For cohort with 2 or more injuries & 0.241 & 0.081 & 0.719 \\
\hline
\end{tabular}

Type of injuries

Almost a quarter of those injured $(23.5 \% \mathrm{p}<0.001)$ sustained muscle injuries which made up about half of all injuries (51\%). Bruising was less common with 10.6\% of the respondents sustaining $34 \%$ of all injuries. Other injuries reported include cuts $(5.9 \%)$, fracture and ligament injuries (1.2\% each), all of which made up the remaining $15 \%$ of injuries (Table 3 ). 
Table 3: Mechanism and type of injury reported by respondents

\begin{tabular}{|lllllll|}
\hline Activity & Cut & $\begin{array}{l}\text { Graze/ } \\
\text { bruise }\end{array}$ & $\begin{array}{l}\text { Muscle } \\
\text { injury }\end{array}$ & Fracture & $\begin{array}{l}\text { Ligament } \\
\text { injury }\end{array}$ & Total \\
Tackle & 1 & 4 & 6 & 0 & 0 & $11(13.8 \%)$ \\
Turning & 0 & 2 & 3 & 0 & 0 & 5 \\
Landing & 1 & 5 & 4 & 1 & 0 & $11(13.8 \%)$ \\
Running & 1 & 4 & 8 & 1 & 1 & $15(18.8 \%)$ \\
Heading ball & 2 & 3 & 1 & 0 & 0 & 6 \\
Jumping & 0 & 2 & 1 & 0 & 0 & 3 \\
Overuse & 0 & 2 & 3 & 0 & 1 & 6 \\
Collision & 1 & 3 & 9 & 1 & 0 & $14(17.5 \%)$ \\
Kicking ball & 0 & 0 & 4 & & 1 & 5 \\
Burns & 0 & 2 & 2 & 0 & 0 & 4 \\
Total & 6 & $27(34 \%)$ & $41(51 \%)$ & 3 & 3 & $80(100 \%)$ \\
\hline
\end{tabular}

\section{Location of injury}

The knee was most commonly injured $(16.5 \%, \mathrm{p}<$ $0.001)$ followed by the ankle (11.8\%). The leg, foot and calf $(9.4 \%$ each) were also injured. Injuries to the lower $\operatorname{limb}$ totalled $56.5 \%$ compared to upper limb injuries $(17.8 \%)$. Injuries to the head, neck, face, groin and trunk made up a quarter of all injuries.

\section{Severity of injury}

Injury severity was defined as the number of days that elapsed between the dates of injury to the date the players returned to full participation in soccer as defined by Fuller et $\mathrm{al}^{22}$. Only four respondents stopped participating in soccer as a result of injury. Of the four, three participants had severe injuries and one had moderate injuries.

\section{Causes of injury}

The majority of the injuries were sustained due to collision with another player at $12.9 \%(\mathrm{p}<0.001)$ followed by running at $11.8 \%$, tackling and landing at $9.4 \%$ and $7.1 \%$ respectively. Players were also injured when turning $(5.9 \%)$, kicking the ball $(4.7 \%)$, overuse, heading the ball and burns (3.5\% each) and jumping (2.4\%).

\section{Relationship between types of injury and mecha- nism of injury}

Types of injuries relating to mechanisms of injury sustained are presented in Table 3. Since one or more mechanisms of injury could be reported, the total percentages did not equal $100 \%$. It is shown that running $(\mathrm{p}<0.001)$ at $18.5 \%$ followed by collision with player $(\mathrm{p}<0.001)$ at $17.3 \%$ as well as tackle $(\mathrm{p}=0.002)$ and landing $(\mathrm{p}=0.139)$ at $13.6 \%$ resulted in the most of the muscle injuries (52\%). Bruises $(21 \%)$ were mostly sustained during landing $(\mathrm{p}=0.012)$.

\section{Management of injuries}

In terms of self-treatment, ice (49.0\%) and rest (17.6\%) were the main treatment modalities used. Of the 31 injured players, $54.5 \%$ players had been advised to rest, $34.1 \%$ were allowed to engage in limited sport activity and eleven percent continued to participate fully in sport activity after sustaining an injury. Almost thirty one percent of respondents reported having access to healthcare during training or play. Medical or paramedical services $(47.7 \%)$ followed by sport massage therapy $(14.9 \%)$ were most commonly sought to manage the injury. The coach $(18.2 \%)$ was the second most commonly consulted for advice.

\section{Exercises or activities performed during training}

The participants reported activities performed during training. The majority of the participants did warmups $(85.9 \%)$, jogging $(76.5 \%)$ followed by stretching $(71.8 \%)$ during training.

\section{Use of equipment}

The majority of the respondents $(63.5 \%)$ played with soccer boots while $34.1 \%$ played using trainers. Out of the 31 injured participants only $14.1 \%$ wore soccer boots and protective guards when the injury occurred.

\section{Comparison of injuries during training and match- es}

Almost fifty two percent of the respondents participated in one to five matches over the study period and $40 \%$ participated in one to five training sessions during 
the same period. Of the 31 participants who reported injuries, more participants (35.5\%) were injured during training than during the matches $(22.9 \%)$. The rate of injuries during training and matches were significant $(p<0.001)$. Significantly more muscle injuries were sustained during training than during matches $(p<0.001)$ but more bruises occurred during matches $(\mathrm{p}<.001)$

\section{Protective guards worn during training and match- es}

The majority of the players did not use any protective gear during matches. The most commonly used protective guards were shin guards by players during matches $(47.1 \%)$ and in training $(22.4 \%)$. The ankle guards were reported as the second most used protective equipment during matches at $22.4 \%$ and training at $4.7 \%$. Knee guards were worn the least during matches at $9.4 \%$ and in training at $3.5 \%$. It is noted that shin (49.4\%), ankle $(77.6 \%)$ and knee $(88.2 \%)$ guards were not commonly worn during matches and training.

\section{Discussion}

The usable response rate in this study was $49 \%$ and was higher than that reported in previous studies ${ }^{15,16}$. A possible reason for the acceptable response rate is that the soccer players had to complete the questionnaire during break-time and at the soccer fields at a given time, because they were not allowed to take the questionnaire home. However, only questionnaires that were complete were included in the analyses.

One sub-district showed a higher response rate (82.4\%) compared to the other $(17.6 \%)$ possibly due to the fact that the first sub-district had more female players than the second sub-district. A considerable number of second sub-district players had other sport commitments, experienced transport problems or did not receive parental permission to participate. The higher proportion of African Black players can be attributed to their population density in the selected district accounting for $73.8 \%$ as compared to the White population at $6.6 \%$, Indian at $16.6 \%$ and Coloured at $2.5 \%{ }^{17}$. The mean age of the female high school soccer players was 15.85 years with a standard deviation of 1.32 years which was similar to other studies reporting on young soccer play$\operatorname{ers}^{15}$.

There was no statistically significant $(p<0.83)$ difference between the injured players and uninjured players with respect to age, race, district, player position and other sports played. Additionally, the results indicated that, players from both districts had similar characteristics.

The overall prevalence of injuries was $36.5 \%$ and $22.9 \%$ (during training and matches) in this study. This is congruent with previous studies stating that the number of injuries was high in female soccer players which ranged from $55-87 \% 0^{7,8,18,19}$. The definition of injury and injury prevalence adopted in this study was similar to those used in some other studies ${ }^{20,21}$. In this study, injury was defined as any physical complaint suffered by players that resulted from a soccer match or training, with the need for medical attention or time lost from soccer activities $^{22}$.

\section{Types of injuries.}

Muscle (strain) injury was the most common injury type reported in this study. This finding is in agreement with other studies ${ }^{6,7,23,24}$. Running, collision with player and tackle was significantly associated with muscle injury in this study. Bruising or contusion was the second most common type of injury sustained, similar to that reported by Owoeye et al. ${ }^{10}$ and Mahlangu ${ }^{6}$ in female soccer players. This may probably be explained by the fact that the level of participation (training and matches) was higher in the above studies which was congruent with this study.

\section{Location of injury}

More lower extremities injuries were reported compared to those in the upper extremities. This finding is similar to that of other studies that have found lower extremity injuries representing $60 \%-87 \%$ of the total injuries suffered by soccer players $6,7,10,16$. Other investigators $^{24,25}$ believe that female players are more likely to sustain injuries to their knees than to ankles. However, the findings of this study disagrees with studies conducted by Le Gall et al. ${ }^{8}$ who reported that the ankle was the more commonly injured followed by the knee joint. The frequency of knee and ankle injuries may be attributed to the task of dodging, jumping and landing which is different in young females.

\section{Severity of injury}

The definition of severity of injury adopted in this study was similar to the one used in other studies ${ }^{22}$. The severity of injury was categorized as minor, moderate and severe depending on the length of time needed for recovery. Four players sustained moderate to severe 
injury soccer injuries in this study, similar to another study $^{7}$. Injuries to players can have a significant effect on the performance and confidence of the team ${ }^{15}$.

\section{Mechanism of injury}

Collision with another player and tackle as well as running (non-contact) were the common mechanisms of injury. This is similar to the findings of Chomiak et al. ${ }^{26}$ who reported that $53.6 \%$ of play involved no body contact and $46.4 \%$ of injuries were caused by contact. Rahnama et al. ${ }^{27}$ suggested that some playing actions like receiving a tackle, making a tackle, and receiving a charge were associated with higher risk for injury. Agel et $\mathrm{al}^{2}$ showed that most injuries that occurred during matches' resulted from contact with another player whereas during training, it resulted from non-contact.

\section{Management of injuries, medical and nutritional profile}

Soccer players in this study did not have access to health care professionals on the field and self-reporting could have led to inaccurate under or over reporting and management of the injuries. Arnason et al. ${ }^{29}$ agreed that the limited attendance of healthcare professionals during training may lead to underestimation of minor injuries causing players to miss one or two training sessions.

The medical sports team should ideally comprise of a team doctor or physician, physiotherapist, masseur, dietician, and sports psychologist. The injured player should receive treatment and be healed. The respondents in the current study were dependant on the coach for support and advice, in contrast to other studies where health care professionals were at hand when support or advice was required.

\section{Injury risk factors}

The use of protective equipment was shown to decrease injury rates. This finding should be used with caution due to the small sample size and limited use of shin guards as reported by Bir et al. ${ }^{30}$. In this study, there were few leg or shin injuries which were congruent with a study by Mtshali et al. ${ }^{16}$. Contact rather than overuse has been linked to acute shin injuries. The ankle injuries were associated with wearing shoes with studs. Not wearing shin guards has been shown to have a direct correlation to leg injuries ${ }^{21}$. Hawkins and Fuller ${ }^{12}$ reported that despite the importance of shin guards in injury prevention and their compulsory wearing in both training and matches, 28 players used shin and ankle guards only in competitive matches and 51 did not wear protective equipment in training. However, 30 of these players agreed that wearing shin pads reduced the risk of lower leg injury but 53 players said that they were not encouraged by the coaching staff to wear shin guards during training.

This study indicated that ankle guards were worn most often compared to the knee guards in matches rather than in training. Therefore, given the fact that the knee joint was reported as the most affected body part in this study, it can be believed that the lack of usage of the knee guards could influence the occurrence of knee injuries in female soccer players without ruling out other factors such as playing surfaces and shoes.

\section{Comparison of injuries occurring in training and matches.}

The number of injuries mostly occurred in training as compared to matches. These findings were different from that reported by other investigators ${ }^{18,28}$ who stated that injury incidence rate in elite female soccer players was high during soccer matches. However, Wong and Hong $^{31}$ found that the injury rates were higher during matches for male players while that for female players were higher during training. The correlation between injuries sustained during training and those sustained during matches was significant $(p<0.000)$. Similar findings have been reported by Twizere ${ }^{13}$.

\section{Conclusions}

This study revealed that injury prevalence was high $(94 \%)$ in female high school soccer players. The lower limb was affected more than any other part of the body with more knee and ankle injuries. The common types of soccer injuries in female players were muscle strains and bruises. The defenders and midfielders were most injured compared to goalkeepers and strikers. Injury mechanisms that seemed to account for the most injury in this study were collision with player and running. The injuries occurred more commonly during training than during matches.

\section{References.}

1. Puckree T, Naidoo P, Naidoo T, Pillay P. Underweight and Overweight in Primary School children in eThekwini district in KwaZulu Natal, South Africa. African Journal of Primary Health Care and Family Medicine 2011; 3: 1-6

2. Govender P. Plan to fight obesity among children. Sunday Times 2010; 16: 12 . PubMed http://www. 
sport24.co.za/OtherSport/New-plan-for-sport-inschools-201102034

3. Schlenker M. Girls and football, South African Catalyst. 2013; Available at http://www.iwg-gti.org/catalyst/october-2013/girls-and-football-sa/ accessed on 17 March 2014

4. FIFA. Womens football today: Information and statistics on womens football from the member associations of FIFA.http://resources.fifa.com $/ \mathrm{mm} / \mathrm{docu}-$ ment/afdeveloping/women/93/77/21/factsheets.pdf. Accessed 19 October 2015

5. Tremblay MS, Gray CE, Akinroye K, Harrington DM, Katzmarzyk PT, Lambert EV et al. Physical Activity of Children: A Global Matrix of Grades Comparing 15 Countries. Journal of Physical Activity and Health, 2014;11(Supp 1): S113-S125

6. Mahlangu LL. Lower limb injuries in teenage girls playing soccer. 2006; Unpublished Masters of Physiotherapy (Sports Medicine) thesis, Pretoria: University of Pretoria.

7. Hawkins R D, Hulse MA, Wilkinson C, Hodson A, Gibson M. The association football medical research programme: an audit of injuries in professional football. British Journal of Sports Medicine 2001; 35(1): 43-7

8. Le Gall F, Carling C, Reilly T. Injuries in young elite female soccer players: an 8-season prospective study. American Journal of Sports Medicine 2008; 36(2): 276 -284 9. Steffen K, Emery CA, Kang J, Bizzini M, Dvorak J, Finch C F. et al. High adherence to a neuromuscular injury prevention programme (FIFA 11+) improves functional balance and reduces injury risk in Canadian youth female football players: a cluster randomised trial. British Journal of Sports Medicine 2013; 47: 794-802

10. Owoeye OBA, Nwachukwu AL, Akinbo SRA. Injuries in Nigerian National Female Footballers at the 2008 Beijing Olympic Games, China: A prospective case study. African Journal of Physiotherapy and Rehabilitation Sciences 2012; 4(1-2): 57-61

11. Holschen JC. The Female athlete. South Medical Journal 2004; 97(9): 852-858

12. Hawkins R D, Fuller C W. An examination of the frequency and severity of injuries and incidents at three levels of professional football. British Journal of Sports Medicine 1998; 32(4): 326-332

13. Twizere J. Epidemiology of soccer injuries in Rwanda: A need for physiotherapy intervention. 2004; Unpublished Master's thesis in: Physiotherapy. Cape Town, University of Western Cape.

14. Archary NW. A profile of soccer injuries in selected league amateur indoor and outdoor soccer players in the greater Durban area. 2008; Unpublished Master of Technology thesis. Durban: Durban University of Technology.

15. Woods C, Hawkins R, Hulse M, Hodson A. The Football Association Medical Research Programme: an audit of injuries in professional football-analysis of preseason injuries. British Journal of Sports Medicine 2002; 36: 436-441

16. Mtshali PTS. Common lower extremity injuries in female high school soccer players in Johannesburg east district. 2007; Unpublished Master of Science (Physiotherapy) thesis. Johannnesburg: University of the Witwatersrand

17. Statistics South Africa. Mid-year population estimates, South Africa [online]. 2007. [http://www.statssa. gov.za] (Retrieved on 9 September 2013)

18. Faude O, Junge A, Kindermann W, Dvorak J. Injuries in female soccer players: A prospective study in the German national league. American Journal of Sports Medicine 2005; 33(11): 1694-1700

19. Emery CA, Meeuwisse WH, Hartmann SE. Evaluation of risk factors for injury in adolescent soccer: Implementation and validation of an injury surveillance system. American Journal of Sports Medicine 2005; 33(12): 1882-1891

20. Frantz JM, Amosun SL, Weitz W. Injuries among adolescent soccer players during an inter provincial tournament in South Africa. South African Journal of Sports Medicine1999; 6(2): 13-15

21. Dvorak J, Junge A. Football Injuries and Physical Symptoms. A Review of the Literature. American Journal of Sports Medicine 2000; 28(5-Suppl): S3-9

22. Fuller, C.W., Ekstrand, J., Junge, A., Anderson, TE., Bahr, R., Dvorak, J. et al. Consensus statement on injury definitions and data collection procedures in studies of football (soccer) injuries. British Journal of Sports Medicine 2005; 40(3): 193-201

23. Walden M, Hagglund M, Ekstrand J. UEFA Champions League study: a prospective study of injuries in professional football during the 2001-2002 seasons. British Journal of Sports Medicine 2005; 39: 542-546

24. Hägglund M, Waldén M, Ekstrand J. Injuries among Male and Female Elite Football Players. Scandinavian Journal of Medicine and Science in Sports 2009; 19 (6): 751752

25. Östenberg A, Roos H. Injury Risk Factors in Female European Football. A Prospective Study of 123 Players during one Season. Scandinavian Journal of Medicine Science and Sports 2000; 10(5) 279-285

26. Chomiak J, Junge A, Petersen L, Dvorak J. Severe injuries in football players. American Journal of Sports Medicine 2000; 28:S 
27. Rahnama N, Reilly T, Lees A. Injury risk associated with playing actions during competitive soccer. British Journal of Sports Medicine 2002; 36: 354-359.

28. Agel J, Evans TA, Dick R, Putukian M. Descriptive Epidemiology of Collegiate Men's Soccer Injuries: National Collegiate Athletic Association Injury Surveillance System. Journal of Athletic Training 2007; 42(2): 270-277.
29. Arnason A, Sigurdsson SB, Gudmundsson A, Holme I, Engebretsen L, Bahr R. Risk factors for injuries in football. American Journal of Sports Medicine 2004; 32(1): S5-S16.

30. Bir C, Cassatta J, Janda D. An Analysis and Comparison of Soccer Shin Guards. Clinical Journal of Sports Medicine 1995; 5(2): 95-9.

31. Wong P, Hong Y. Soccer injuries in the lower extremities. British Journal of Sports Medicine 2005; 39: 473482. 